\title{
Research on Mechanism and Ways to Application of Intermittent Training Method in High School Swimming Team Training
}

\author{
Anqiang Hu \\ Sichuan Tourism University, Chengdu Sichuan, 610100, China
}

Keywords: Intermittent training method, High school swimming team, Application mechanism path research

\begin{abstract}
By means of literature, expert interview, logical analysis and other research methods, research shows the application of intermittent training method in high school swimming team referenced excessively upon higher level professional teams, which means pertinent training mechanism and path are missed. While based on principles of comparative demands on different level, suitable load and timely recovery sports training, this paper analyzed mechanism and path to application of intermittent training method in high school swimming team training, proposed application methods of "adequate use of incentive and health oriented, individual differences determine the personalized training needs, training load arrangement application of intermittent method in the training system, and periodic arrangement and swimming technology cooperation”, to provide practical use of intermittent training method in ordinary high school swing team.
\end{abstract}

\section{Introduction}

As a traditional sports competition, swimming reflects the characteristics of good fitness and the coordination of body and mind. It has great effect on promoting the physical health and all-round development of human beings, and is deeply loved by students. Therefore, many universities pay great attention to the construction of swimming courses, specially built indoor and outdoor swimming stadiums, including swimming courses into the required courses of physical education, and set up swimming teams to guide the development of courses. But every university swimming team is built by both high level and special selected students and ordinary selected students, which cause a huge difference in the level of basic principles, therefore the choice of training methods must comply with basic training principles. Therefore, this paper selects the most commonly used Intermittent training method as the research object, and explores its theoretical mechanism and path for the training of college teams, so as to provide references for scientific training.

\section{Application Status of the Intermittent Training Method in College Swimming Team}

Intermittent training method is the most common and widely used method of training, but by the current physical condition and quality of the swimming coach, many coaches of high level sports training arrangements to borrow to ordinary university on professional athletes training, often in groups as a unit, high strength, high load, ignoring the individual differences of students, the lack of personalized and practical, which leads to the swimming training quality is low, the effect is poor, the theory of mechanism to discuss college swimming team training Intermittent training method and implementation path.

\section{Definition of Intermittent Training Method}

Intermittent training method refers to the strict training of movement structure and load intensity and intermittent time so as to keep the body in a state of incomplete recovery. In general, the distance between main items or short distances from main items is usually composed of factors such as distance, repetitions or groups, intensity, intermittent time, intermittent time, and ways of completion. 


\subsection{Intermittent Training Method}

Intermittent training method is most basic and commontraining method in swimming teams training both here and abroad. It accelerates metabolism through training, improves anaerobic threshold and maximal oxygen uptake, and improves athletes' ability of Phosphor gen, psychology and energy supply. The application difficulty is not very high , but need higher comprehensive quality of the coaches, Swimming Teachers in general colleges and universities only a small part of the professional training experience, experience of Intermittent training method, but can use the scientific and effective training methods of the teachers is not much, so the teacher in order to pursue success, blindly increase the amount of training and strength training, not only did not improve the effect, instead of causing bodily injury to athletes.

\subsection{Theoretical Mechanism of Intermittent Training Method in College Swimming Team Training}

Use of intermittent training method must follow scientific theoretical guidance, under the basic of ensuring team body health, construction realistic path to effectively achieve the training target and requirement of colleges. Intermittent training method is a method system which belongs to the category of sports training. It must conform to the basic principles of sports training. Therefore, to establish the theoretical mechanism of training Intermittent training method in swimming teams of universities and colleges, we must explore the theoretical framework of training principles of sports training.

\section{Training Principle of Steering Excitation and Healthy Insurance}

Swimming is periodic motion, the higher requirement to the physical function, the intermittent training in swimming training is of high strength, high load training, immediately after exercise heart rate remained at about 180 times per minute, put forward a challenge to the athlete heart and physical endurance athletes, to ensure long-term training, we need continuous motivation to actively participate in the training of athletes. Competitive sports itself is to tap athletes' competitive potential, and it will bring risks to athletes' physical and mental health. Therefore, interval training for swimming teams is to motivate players to actively train from two aspects, internal and external, under the premise of guaranteeing their physical and mental health.

\subsection{Principle of Competitive Needs and Different}

Competition is core of competitive sports, and it is also the ultimate goal of training. All sports training is carried out around the competition. To get the expected results in the competition needs to start from actual combat and arrange training systematically and scientifically. Because there are individual differences in the training of athletes, so it should be treated differently in Wen Yuhong's doctoral thesis "personalized needs and organizational strategy" of high level swimming training of contemporary outstanding athletes and tour around the typical amount of personalized comparison; the amount of exercise in 6000-16000 meters, 50000-100000 meters, the amount of training week. That is: the amount of sport and the training requirements of the same project athletes are also distinctly different.

\subsection{Principle of Suitable Load and Refresher Training}

The load of swimming training is determined by the quantity and intensity. In the use of Intermittent training method training, swimming teams usually use the best results, heart rate, blood lactic acid and so on to evaluate the exercise intensity. The best results for the $100 \%$ assessment of strength $(100 \%-Z)$, which $\mathrm{X}=\mathrm{YY}(\mathrm{X}=$ score requirements; $\mathrm{Y}=$ best practice; $\mathrm{Z}=$ completed the required strength). Immediately after exercise, the heart rate can be divided into three levels (intensity 30 times more than /10 seconds), moderate intensity 25 times /10 seconds, small intensity 20-21 /10 seconds, and can also be evaluated by five level strength in Russia. The level of blood lactic acid represents the level of sports. In the application of blood lactic acid in juvenile swimming, Lu pointed 
out that the relationship between swimming athletes' lactic acid threshold intensity and peak value of lactic acid is directly proportional to their performance. For team sports in universities is relatively low level, and therefore cannot refer to the high level sports team training in the use of Intermittent training intermittent method, according to the psychological and physiological characteristics of players, appropriate to reduce the strength and reduce the number of outstanding, personalized features and to plan training of intermittent training scientifically arrange the swimming team.

\subsection{Principle of Periodicity and Systematic Continuity}

Ordinary university swimming team arrange training courses3-4 times per week, each course should last 90 minutes, winter and summer vacations interrupt training, some results obtained during the period of school Intermittent training method for training interruption is greatly reduced, weakening the superimposed effect of practice, the players of the training level and athletic performance decline. In the systematic and periodic arrangement, we should combine the actual situation of swimming teams in Colleges and universities, consider the continuity of training comprehensively, guarantee the systematic and periodicity of intermittent swimming training, highlight the characteristics of "individuation and practicality", and ensure the achievement of swimming interval training.

\section{Practical Path College Swimming Team Training of Intermittent Training Method}

Swimming is a very physically demanding sport, swimming and intermittent training is very hard, four principles of training teachers in reality, flexible use of sports training, according to the actual situation of the team making training plan and adapt to the intermittent swimming training can achieve good long-term development and security training the effect of the.

\subsection{Use Path of Steering Encourage and Healthy Ensure Correctly}

Teachers are dominant in intermittent swimming training, students are the main body, between student and teachers is a kind of interactive training relationship, the teacher's role is to correctly guide the students, while students are there to accept teacher's order. Student will actively participate in training after resonance with teacher, under constant motivation encouragement. First of all, teachers should set clear goals for interval training intensity and amount of exercise, and make clear goals for swimming competition plan requirements. In the training process, we should constantly enhance target awareness and deal with all kinds of relationships so as to keep players from being disturbed. Secondly, players continue to enjoy the results achieved in phased training. Under the guidance of teachers' psychological guidance, they always have confidence in the prospect of intermittent training, and participate in training consciously and voluntarily. Finally, to ensure the physical and mental health of the players. Only under the premise of ensuring the physical and mental health of the players can the motivation be formed.

After intermittent training, physical energy consumption is large, and fatigue is easy to occur. To ensure the physical and mental health of the players, various rehabilitation methods must be adopted, such as training, rehabilitation, medicine, biology, psychology, nutrition, etc.

\subsection{Individual Discrepancy Determines the Needs of Individualized Training}

Everyone is on the individual, each individual in the training of independent physiological function are different, so in the process of training the distinction, the movement of a similar level of players together, can be divided into A group, B group, $\mathrm{C}$ group or more groups, according to the characteristics of intermittent training plan making with suitable, group training.

The swimming team consists of members aged around 18-23, the team's athletic ability and technical level uneven, they have in common is not experiencing a high strength and large load training is difficult to complete the high intensity interval training, they are in the process of training, blood lactate anaerobic threshold is relatively low; motion the amount and intensity of training on the ability to adapt to lower, slower recovery, performance is relatively poor, in the intermittent training 
plan should be treated differently, to make the number and intensity interval according to individual characteristics. For example, in a class, 100 meter distance training is divided into 3 groups: group A (6X100) X2, intensity 80\%, interval 25 seconds. In group B (5X100), group X2, the intensity was $75 \%$, and the interval time was 30 seconds. Group C (4X100) group X2, strength 70\%, interval time 35 seconds; in 100 meters self-swimming swimming: group A, 1 minutes 40 seconds; B group, 1 points 50 seconds; C group, 2 minutes.

\subsection{The Application of Exercise Load in Intermittent Training Method}

In the actual application of swimming team, according to the actual situation of the players, the size of the load is set up. For example, the best exercise score is $100 \%$, the exercise load intensity is $\mathrm{X}=\mathrm{Y}+\mathrm{Y}(100 \%-\mathrm{Z})$, and the interval is 50 meters breaststroke. The best result of group $\mathrm{A}$ is 34 seconds. When a group of $10 \mathrm{X} 50$ rice breaststroke training is required to have a strength of $80 \%$, the result of each 50 meter breaststroke is $\mathrm{X}=34+34(100 \%-80 \%)=40.8 \mathrm{sec}$. The results of group B C were calculated by analogy. In the evaluation of heart rate, with the highest heart rate (immediately after exercise heart rate remained at 160 times / min), the lowest rate of not less than 130 times / min. The intensity of movement can also be arranged by the Russian five stage strength of two (21-25 /10 seconds) and three (25-30/10 seconds).

\subsection{The Cooperation Between Systematic and Periodic Arrange, with Swimming Terminology}

Swimming technology is the basis for athletes. In training, the body always keeps a good streamlined pattern, which is the premise to reduce resistance and maintain momentum. Good technology and abundant physical strength are the guarantee for excellent performance. In general, the swimming team of colleges and universities is less than 9 months of training throughout the whole year. The training effect is weakened due to the interruption of training in the winter and summer vacation, which destroys the power stereotype and affects swimming technology and physical reserve. Long time without training, resulting in rigid deformation of the technical movement, the level of physical energy decreased, affecting the effect of intermittent training. How to ensure the systematic and periodicity in constant intermittent training is a problem need to be solved.

The whole year is divided into two semester plans. The 4 month is a large cycle. When arranging the interval training plan, the system is also strictly in accordance with the preparation period, the competition period and the recovery period. In order to make up for lack of training and continuity in school, arrange winter and summer vacation training plan, train 90 times a week for 2 times, check the sports plan through mobile phone, save screen shots and start school as a whole. To ensure the establishment of a complete interval training program cycle, and the fluency of swimming technology.

The systematic and periodic arrangement of intermittent training is closely related to swimming technology. Only by guaranteeing the continuity of training system can we ensure the smoothness of swimming skills. Therefore, in the interval training process, we should always remind the players to keep their technical movements, not to relax the pursuit of excellent swimming skills because of fatigue, to play every skill and make themselves enjoy relaxed swimming.

\section{Conclusions}

The use of intermittent training mechanism in college swimming team training should not over prefer with high level professional team training, it have to follow guidance of the principles, correctly handle the incentive and health promotion, dealing whit differential of personality, to arrange training load, the establish a complete cycle of training plan, set up a "personalized and practical "interval training system on the basis of scientific investigation, to improve the swimming training effectively. 


\section{References}

[1] Tian Maijiu, Liu Jian, and Yanfeng sports training, People's Sports Press 2000.

[2] Cong Ning Li, Li Wenjing, Ma Ji Guang, and other swimming sports, People's sports press 2001.

[3] Wen Yuhong. The demand and the strategy of the organization to diagnose is chemical vascular disease of high level swimming training. Doctoral dissertation, 2006.

[4] Li Yi. Sports game theory, Beijing Sport University Press, 2002,

[5] Lu Hui. Study on the application of blood lactic acid in young swimmers, contemporary sports science and technology, 2017.

[6] Li Zhengrong, Dong Jiukui, Yang Jie. Strengthening the role and movement of Intermittent training method in tennis selective courses in sports colleges and universities, Journal of Chengdu Sport University, 2016.2.

[7] Zhang Wenli. Biological stress and exercise training, Beijing sports science and technology 1984.

[8] Yang Yongqiang. Study on the application of cyclic Intermittent training method to improve the anaerobic endurance of female pilots, Northeast Normal University, 2010. 